\title{
The anti-angiogenic and cytotoxic effects of the boswellic acid analog BA145 are potentiated by autophagy inhibitors
}

\author{
Anup S Pathania ${ }^{1,2}$, Zahoor A Wani ${ }^{1}$, Santosh K Guru' ${ }^{1}$, Suresh Kumarr ${ }^{1,2}$, Shashi Bhushan ${ }^{1}$, Hasan Korkaya ${ }^{3}$, \\ Darren F Seals ${ }^{5}$, Ajay Kumar ${ }^{1}$, Dilip M Mondhe ${ }^{1}$, Zabeer Ahmed ${ }^{4}$, Bal K Chandan ${ }^{4}$ and Fayaz Malik,2*
}

\begin{abstract}
Background: While angiogenesis inhibitors represent a viable cancer therapy, there is preclinical and clinical data to suggest that many tumors develop resistance to such treatments. Moreover, previous studies have revealed a complex association between autophagy and angiogenesis, and their collective influence on tumorigenesis. Autophagy has been implicated in cytoprotection and tumor promotion, and as such may represent an alternative way of targeting apoptosis-resistant cancer cells. This study explored the anti-cancer agent and boswellic acid analog BA145 as an inducer of autophagy and angiogenesis-mediated cytoprotection of tumor cells.

Methods: Flow cytometry, western blotting, and confocal microscopy were used to investigate the role of BA145 mediated autophagy. ELISA, microvessel sprouting, capillary structure formation, aortic ring and wound healing assays were performed to determine the relationship between BA145 triggered autophagy and angiogenesis. Flow cytometery, western blotting, and microscopy were employed to examine the mechanism of BA145 induced cell death and apoptosis. Live imaging and tumor volume analysis were carried out to evaluate the effect of BA145 triggered autophagy on mouse tumor xenografts.
\end{abstract}

Results: BA145 induced autophagy in PC-3 cancer cells and HUVECs significantly impeded its negative regulation on cell proliferation, migration, invasion and tube formation. These effects of BA145 induced autophagy were observed under both normoxic and hypoxic conditions. However, inhibition of autophagy using either pharmacological inhibitors or RNA interference enhanced the BA145 mediated death of these cells. Similar observations were noticed with sunitinib, the anti-angiogenic properties of which were significantly enhanced during combination treatments with autophagy inhibitors. In mouse tumor xenografts, co-treatment with chloroquinone and BA145 led to a considerable reduction in tumor burden and angiogenesis compared to BA145 alone.

Conclusion: These studies reveal the essential role of BA145 triggered autophagy in the regulation of angiogenesis and cytoprotection. It also suggests that the combination of the autophagy inhibitors with chemotherapy or anti-angiogenic agents may be an effective therapeutic approach against cancer.

Keywords: Autophagy, angiogenesis, hypoxia, vascular endothelial growth factor receptor-2 (VEGFR-2), light chain protein 3 (LC3), BA145, Chloroquinone (CQ)

\footnotetext{
*Correspondence: fmalik@iiim.ac.in

'Department of Cancer Pharmacology, CSIR-Indian Institute of Integrative

Medicine, Canal Road, Jammu, Jammu and Kashmir 180001, India

${ }^{2}$ Academy of Scientific and Innovative Research (AcSIR), New Delhi 110001,

India

Full list of author information is available at the end of the article
}

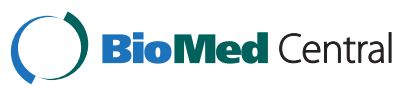

(c) 2015 Pathania et al.; licensee BioMed Central. This is an Open Access article distributed under the terms of the Creative Commons Attribution License (http://creativecommons.org/licenses/by/4.0), which permits unrestricted use, distribution, and reproduction in any medium, provided the original work is properly credited. The Creative Commons Public Domain Dedication waiver (http://creativecommons.org/publicdomain/zero/1.0/) applies to the data made available in this article, unless otherwise stated. 


\section{Background}

Angiogenesis is the physiological process by which new blood vessels are made from a pre-existing vasculature. While angiogenesis plays an important role in tissue repair and in the formation of the placenta during pregnancy, it is also utilized by malignant cells for their growth and metastasis $[1,2]$. Suppressing neoangiogenesis in cancer has been considered an attractive therapeutic option in the era of target based drug discovery, and several anti-angiogenic agents are in clinical development for a number of human malignancies $[3,4]$. Despite the anticipated benefits, angiogenesis inhibitors have failed to produce sustained clinical responses in most patients because of resistance towards these inhibitors. It has been proposed that the activation of cytoprotective autophagy accompanies anti-angiogenic drug resistance [5]. Thus, modulating autophagy may enhance the therapeutic activity of anti-angiogenic drugs.

Autophagy removes the unnecessary and dysfunctional cellular components of the cell via a lysosomal degradation pathway. It protects cells and promotes survival during nutrient starvation, infection, or metabolic stress. There is a complex relationship between autophagy and angiogenesis in different types of cancers. Some studies have revealed that autophagy inhibits the angiogenic vasculature [6,7], while others have suggested that autophagy promotes it $[8,9]$.

To better understand the cross-talk between angiogenesis and autophagy, we focused on the boswellic acid analog BA145. Our group had recently shown that BA145 is the most potent anti-cancer analogue of boswellic acid, and induces robust apoptosis in human leukemia HL-60 cells $[10,11]$. Other studies have reported the anti-metastatic and anti-angiogenic properties of boswellic acids [12,13]. Here we used a well-studied angiogenesis cell model involving human umbilical vein endothelial cells (HUVECs), the highly aggressive and metastatic human prostate cancer cell line PC-3, as well as mouse models of angiogenesis and cancer to better appreciate the role of autophagy on cell survival, angiogenesis, and tumor progression. Our studies indicate that autophagy plays an important role in cytoprotection by inducing an angiogenic signaling cascade, and that autophagic inhibitors in combination with cytotoxic agents overcome this cytoprotection, thus revealing a previously unknown utility of boswellic acids in cancer therapies.

\section{Results}

\section{BA145 exhibits antiproliferative and anti-angiogenic properties}

To determine its antiproliferative potential, both PC-3 cells and HUVECs were treated with different concentrations of BA145 for 24 and $48 \mathrm{~h}$. Proliferation was monitored by an MTT assay. BA145 treatment inhibited the proliferation of PC-3 cells with IC50 values of 40 and $18 \mu \mathrm{M}$ after 24 and $48 \mathrm{~h}$, respectively (Figure 1A). Similarly, treatment of HUVECs with BA145 indicated IC50 values of 8 and $4 \mu \mathrm{M}$ after 24 and $48 \mathrm{~h}$, respectively. FACS analysis of the BA145 treated PC-3 cells and HUVECs displayed concentration-dependent increases in a SubG1 apoptotic cell population as well as a loss in mitochondrial membrane potential (MMP) (Figures $1 \mathrm{~B}$ and $1 \mathrm{C}$ ). The proapoptotic potential of BA145 was further confirmed by observing a dose dependent increase in cleavage of procaspase-3 and PARP-1 in both PC-3 cells and HUVECs (Additional file 1: Figure S1A).

To evaluate the anti-angiogenic potential of BA145 in vivo, a Matrigel plug assay was performed in C57/BL6J mice and functional blood vessels were quantified spectrophotometrically by using Drabkin's reagent. BA145 treatment inhibited VEGF induced blood vessel formation at a dose of 50 and $100 \mathrm{mg} / \mathrm{kg}$ when given subcutaneously for 9 days (Figure 1D). RAD001 (5 mg/kg) was used as a positive control. Furthermore, in a wound healing assay it was observed that various concentrations of BA145 inhibited HUVEC and PC-3 cell migration (Figure 1E).

\section{BA145 inhibits proliferative and angiogenic signaling in PC-3 cells}

VEGF plays a vital role in angiogenesis. VEGF binds to the cell surface receptors VEGFR-1 and VEGFR-2 and activates downstream signaling leading to proliferation, migration, and survival [14]. Hypoxia in tumor tissues induces hypoxia inducible factor-1 (HIF-1) expression, which acts as a transcription factor of genes involved in hypoxic adaptation, promotion of local neovascularisation, and angiogenesis $[15,16]$. BA145 treatment significantly inhibited VEGF induced expression of VEGFR-1/R-2 and HIF- $1 \alpha / 1 \beta$ in PC-3 cells in a dose dependent manner (Figure 2A). Since PI3K/Akt plays a vital role in VEGF mediated angiogenesis [17], we determined whether BA145 was also able to suppress the activation of this signaling pathway. Indeed, treatment of PC-3 cells with BA145 led to downregulation of Akt, Raptor, mTOR, and its downstream substrates p70S6 Kinase and eIF4E (Figure 2A).

\section{BA145 induces robust autophagy in HUVECs and cancer cells}

During autophagy LC3-II is processed from cytosolic LC3-I and expressed on autophagosome membranes along with simultaneous degradation of p62. It was observed that various treatments of BA145 in PC-3 cells and HUVECs for $24 \mathrm{~h}$ led to significant increases in LC3-II expression and p62 degradation compared to untreated cells (Figure 2B). Time dependent analysis of BA145 treated PC-3 and HUVECs showed that LC3-II accumulation took place after $2 \mathrm{~h}$ along with attendant degradation of p62 (Figure 2F). Acridine orange staining of BA145 treated cells also showed increased formation of acidic 

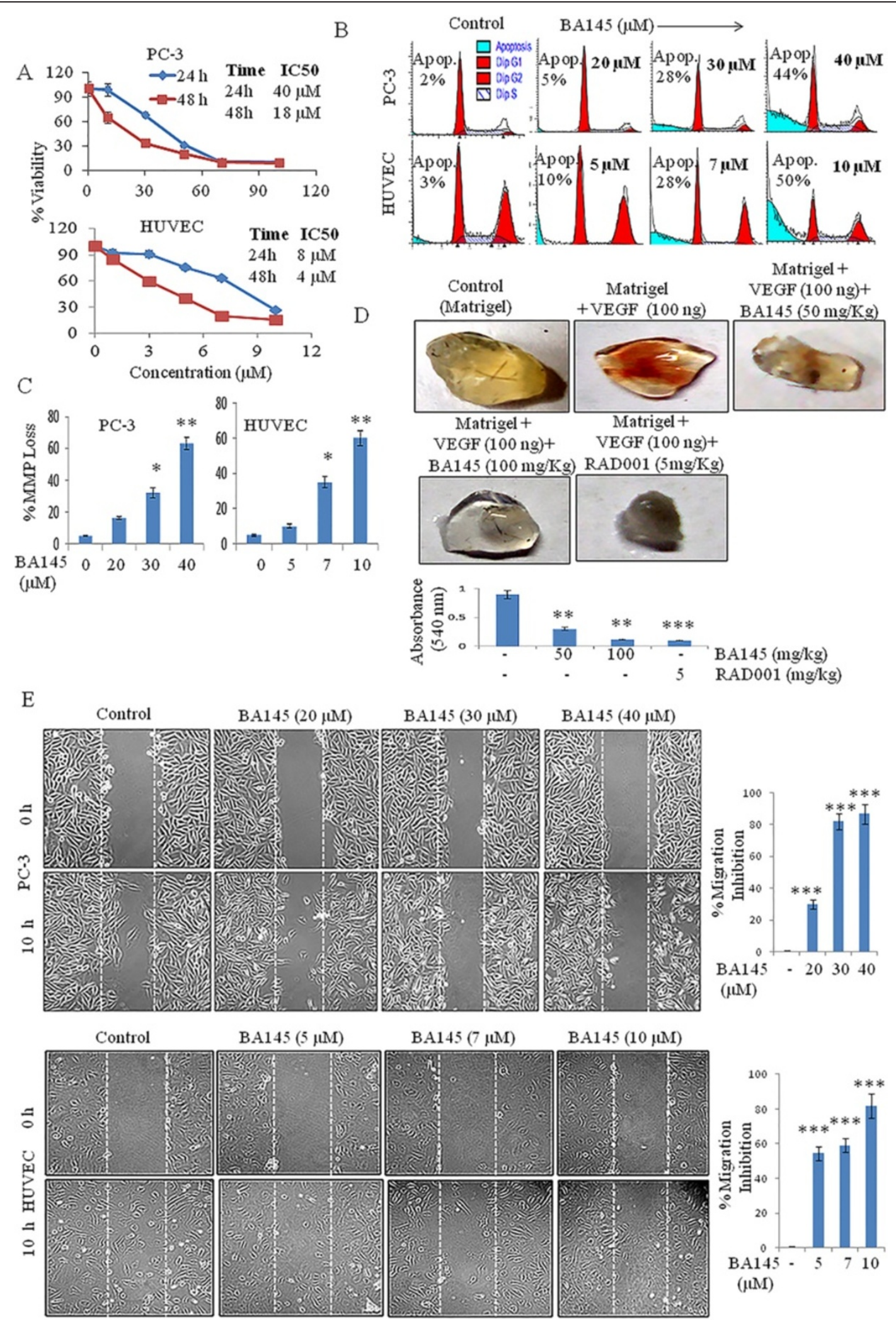

Figure 1 (See legend on next page.) 


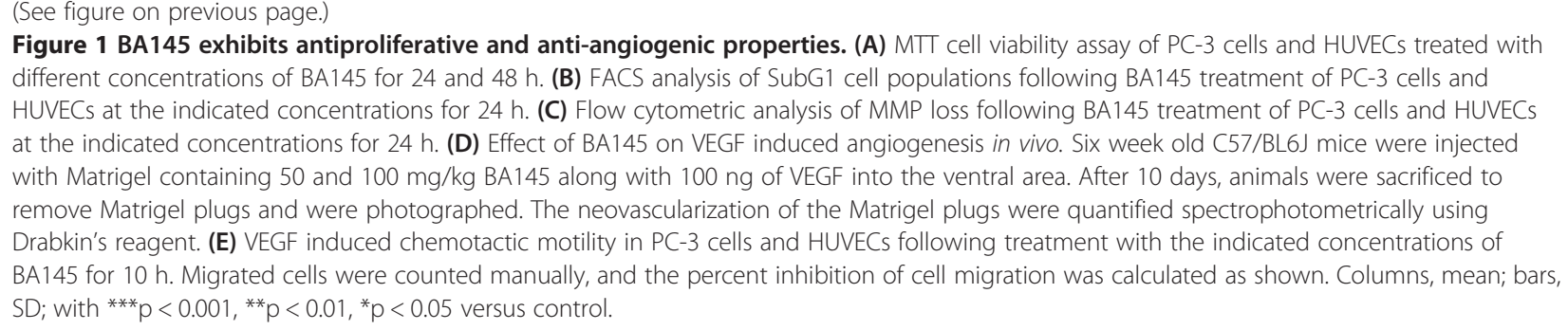

vesicles in the cytoplasm (Figure 2C, Additional file 1: Figure S1B). Furthermore, BA145 treatment caused a significant increase in the punctate distribution of LC3-II in PC-3 cells, supporting the notion that LC3-II was localized to autophagososmes (Figure 2D). In PC-3 cells, autophagy initiation by BA145 treatment was confirmed by the increased capture of red fluorescence emitted by the acridine orange dye through flow cytometry (Figure 2E). These experiments collectively demonstrated the BA145 dependent induction of autophagic flux in PC-3 cells and HUVECs. We simultaneously confirmed that BA145 triggers autophagy associated increases in LC3-II expression and acridine orange positive vesicles among the colorectal cancer cell lines HCT116 and COLO205 (Additional file 1: Figures S2A and S2B).

\section{Inhibition of autophagy accentuates the cytotoxic properties of BA145 and sunitinib}

External stimuli or chemically induced stress in tumor cells often triggers autophagy causing cellular dormancy and developmemt of chemoresistance [18]. Inhibitors of such prosurvival autophagy can improve the efficacy of anti-cancer agents when used in combination. BA145 induced autophagy is protective in nature as inhibition of autophagy potentiates BA145 mediated cytotoxicity in PC-3 cells and HUVECs. The combination of BA145 with various autophagy inhibitors, including ammonium chloride (an inhibitor of autophagosome-lysosome fusion) and LY294002 (an inhibitor of the class III PI3kinase activity required for autophagosome formation), significantly enhanced the antiproliferative potential of BA145 in PC-3 cells (Figure 3A) and HUVECs (Additional file 1: Figure $\mathrm{S} 2 \mathrm{C}$ ) as evidenced by an increase in SubG1 cell populations, MMP loss, and cleavage of procaspase- 3 and PARP1 (Figures 3B, 3C, and 3D, Additional file 1: Figures S2D and S2E). Surprisingly, the combinatorial effect of 3-MA with BA145 did not show any significant alteration on cell survival, though the cleavage of caspase-3 and PARP-1 was considerably increased (Figure 3). To further explore the cytoprotective role of autophagy, we tried to inhibit the expression of key autophagy mediator LC3 in PC-3 cells through siRNA. LC3 silencing promoted the apoptotic effect of BA145 as evidenced by increased procaspase- 3 and PARP-1 cleavage when compared to a scrambled siRNA control (Figure 3E). In order to generalize our findings with other anti-angiogenic agents, we treated PC-3 cells and HUVECs with sunitinib. It was observed that sunitinib treatment decreased cell viability, and simultaneously induced autophagy (Additional file 1: Figures S3A, S3B, and S3C). Moreover, inhibition of autophagy with ammonium chloride and bafilomycin greatly enhanced sunitinib induced cytotoxicity. Note that all the pharmacological inhibitors of autophagy were used at noncytotoxic concentrations during these experiments (Figure 3 and Additional file 1: Figure S3).

\section{BA145 has diverse effects on autophagy among different cancer cell lines}

In the colorectal cancer cell lines HCT116 and COLO205, autophagy induced by BA145 is cytoprotective in nature as co-treatment of BA145 with autophagic inhibitors potentiated its cytotoxicity (Additional file 1: Figures S4A and S4B). This was also true in the MCF-7 breast cancer cell line where autophagy inhibition with LY294002 significantly enhanced BA145 mediated cytotoxicity (Additional file 1: Figures S4D and S4E). In contrast, MDA-MB-231 breast cancer cells respond to LY294002 pre-treatment with decreased cytotoxic effects. In the pancreatic cancer cell lines Mia PaCa-2 and PANC-1, co-treatment of BA145 and LY294002 did not show any significant effect on its cytotoxicity. However, LY294002 further enhanced LC3-II accumulation in BA145 treated Mia PaCa-2 cells. Moreover, LY294002 co-treatment in SH-SY5Y neuroblastoma cells was found to enhance the antiproliferative effect of BA145 (Additional file 1: Figures S4D and S4E). Thus, while the impact of BA145 on autophagy can vary among different cancer cell lines, cancers of widely different origins may also respond similarly to BA145 and thereby be favorable targets for combinatorial treatment with autophagic inhibitors.

\section{Autophagy inhibition potentiates the anti-angiogenic signaling effects of BA145 under both normoxic and hypoxic conditions}

One of the limitations in anti-angiogenic therapies is the creation of hypoxic tumor microenvironments that favor cytoprotective autophagy [19]. To explore the role of autophagy in promoting angiogenesis, we treated $\mathrm{PC}-3$ 


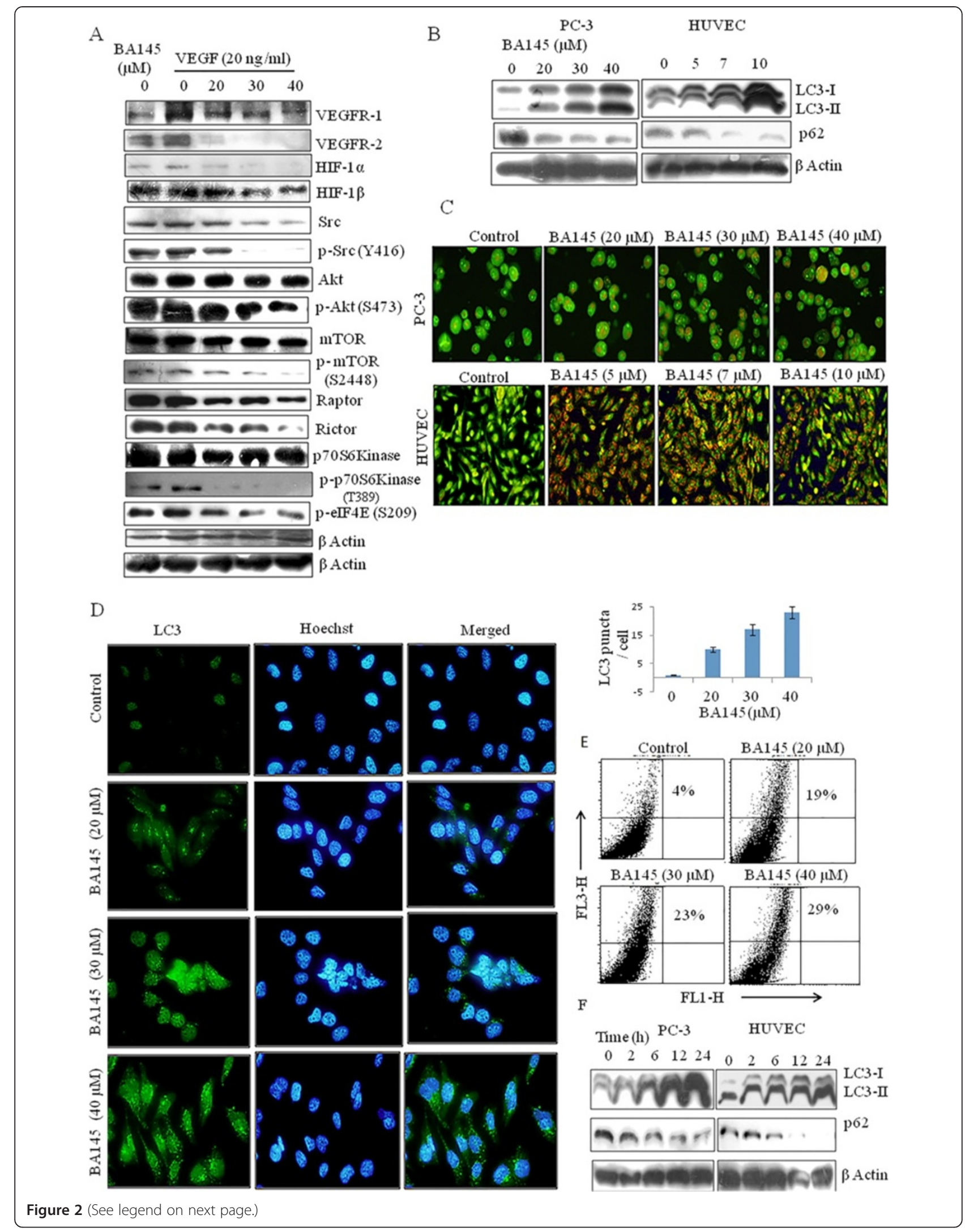


(See figure on previous page.)

Figure 2 BA145 triggers autophagy and suppresses VEGFR signaling in cancer cells. (A) Western blot analysis of the indicated proteins in VEGF activated PC-3 cells with or without BA145 treatment for $24 \mathrm{~h}$. (B) Western blot analysis of the expression of the autophagy marker proteins LC3 and p62 in BA145 treated PC-3 cells and HUVECs after 24 h. (C) Detection of acidic autophagic vesicles in PC-3 cells and HUVECs. After $24 \mathrm{~h}$ treatment with BA145, cells were stained with acridine orange $(1 \mu \mathrm{g} / \mathrm{ml})$ in serum free media for $15 \mathrm{~min}$ and fluorescent micrographs were obtained by microscopy. Autophagy is indicated by the red fluorescence while the untreated control cells are green. (D) Detection of LC3-II protein in PC-3 cells by immunofluorescent microscopy. (E) Quantification of acridine orange positive cells by flow cytometry. PC-3 cells were treated with BA145 at the indicated concentrations for 24 h, stained with acridine orange $(1 \mu \mathrm{g} / \mathrm{ml})$ for 15 min, and analyzed with the FL3-H (red color intensity) and FL1-H (green color intensity) channels of the flow cytometer. (F) Time dependent accumulation of LC3-II and loss of p62 in BA145 treated PC-3 cells and HUVECS.

cells with BA145 along with autophagic inhibitors. The co-treatment of BA145 with ammonium chloride, 3-MA, or LY294002 accentuated the anti-angiogenic properties of BA145 in PC-3 cells. Autophagy inhibitors augmented the inhibition of VEGFR-1/R-2 by BA145, and also augmented the inhibition of downstream signaling molecules like HIF- $1 \alpha / 1 \beta$, Src, and FAK (Figure 4A). This was despite the lack of any significant effect of autophagy inhibitors alone on VEGF signaling in PC-3 cells (Additional file 1: Figure S5A). Silencing of the autophagic gene LC3 also accentuated the anti-angiogenic effects of BA145 in PC-3 and HUVECs (Figure 4B). In contrast, the addition of VEGF $(20 \mathrm{ng} / \mathrm{ml})$ to BA145 treated PC-3 cells increased the expression of LC3-II as compared to BA145 alone,

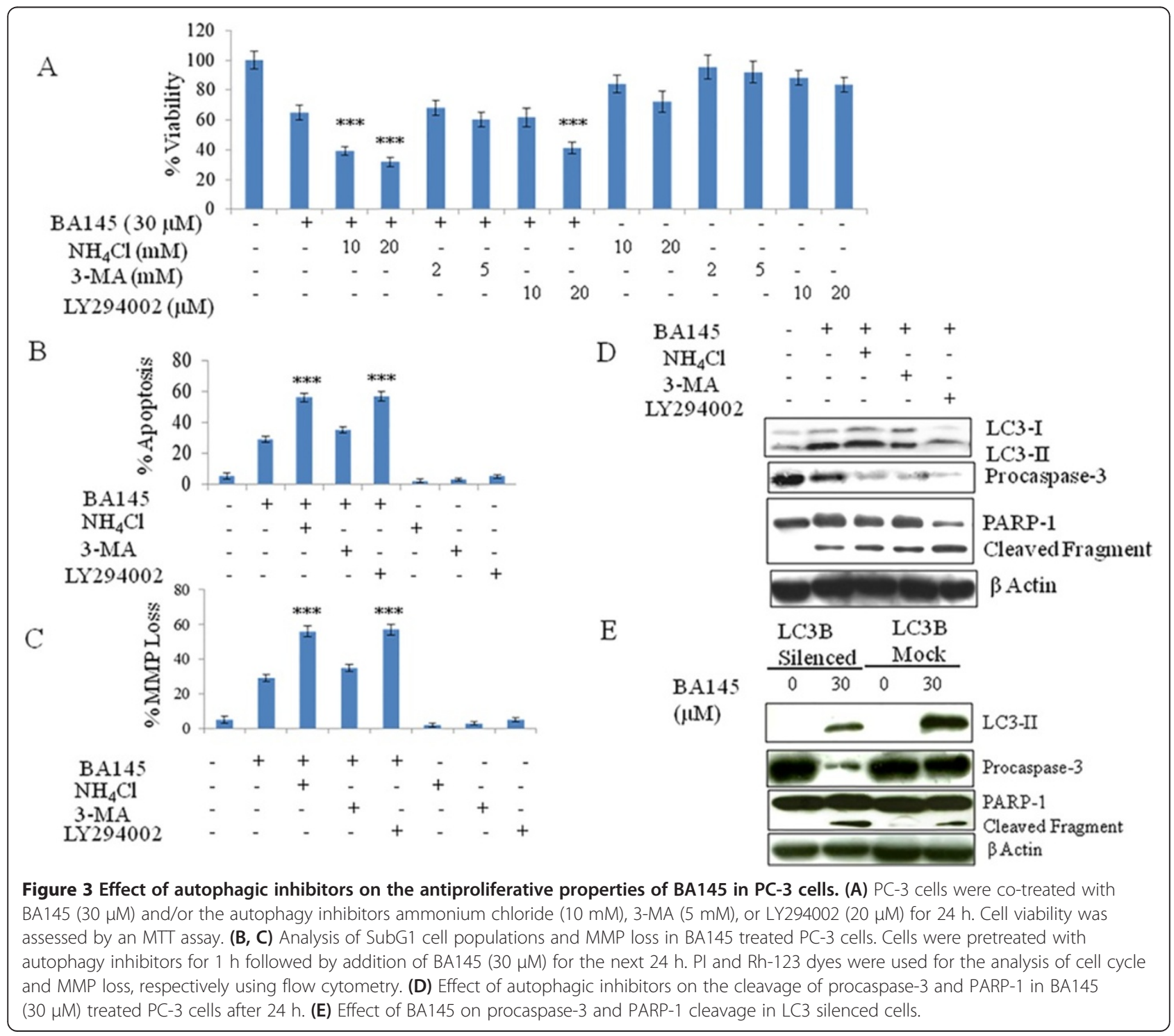




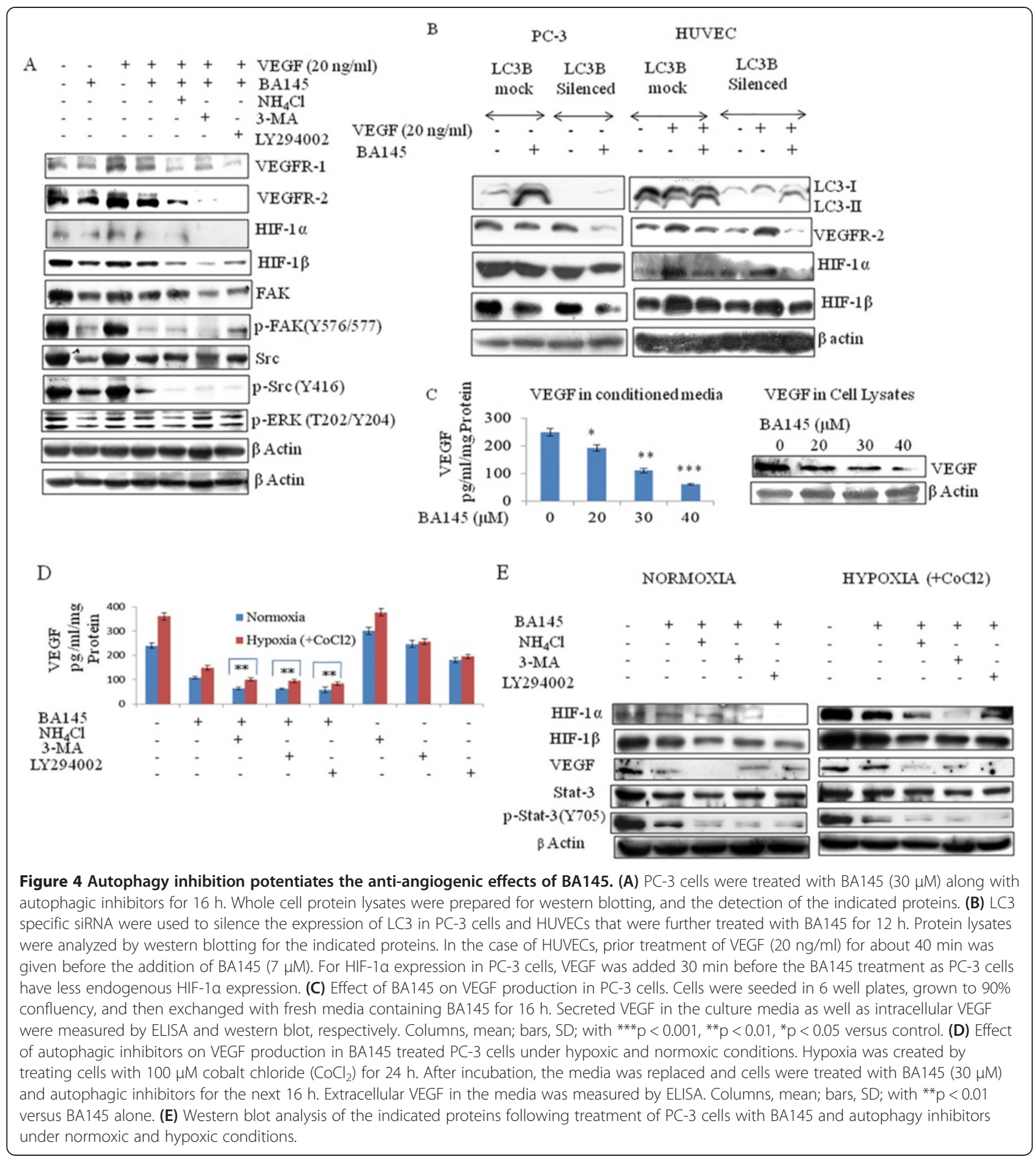

and this was followed by a decrease in the SubG1 cell population, and in procaspae-3 and PARP-1 cleavage (Additional file 1: Figures S5B, S5C, and S5D).

To generalize our findings with other anti-angiogenic agents, we found that the autophagy triggered by sunitinib treatment of PC-3 cells was accompanied by increased expression of VEGFR- 2 and HIF- $1 \alpha$. However, co-treatment of sunitinib with ammonium chloride significantly downregulated the increased expression of these proteins and further potentiated the inhibitory effect of sunitinib on HIF-1 $\beta$ expression as well (Additional file 1: Figure S6).

In order to simulate actual tumor conditions, we next determined the consequences of BA145 mediated autophagy under hypoxic microenvironments. Cobalt chloride was added to the media of PC-3 cells to create hypoxic 
conditions, and this was followed by treatments with BA145 in combination with inhibitors of autophagy. As shown in Figure 4C, BA145 inhibited cellular and secreted VEGF expression in PC-3 cells. This was further potentiated by co-treatment with autophagy inhibitors (Figure 4D). The switching of normoxic to hypoxic conditions in cancers leads to transcriptional activation of the HIF-1 gene, which is responsible for the induction of genes that adapt cancer cells under oxygen starved conditions [20]. PC-3 cells produce low levels of VEGF and HIF- $1 \alpha$ proteins under normoxia, while the expression of these proteins increases under hypoxic conditions (Figure 4E). The treatment of PC-3 cells with BA145 inhibited HIF- $1 \alpha / 1 \beta$ expression under hypoxic conditions and co-treatment with autophagy inhibitors further augmented this effect. Moreover, the effect of autophagy inhibition was also observed on the expression of Signal transducer and activation of transcription-3 (Stat-3), the constitutive activation of which enhances HIF- $1 \alpha$ expression and triggers glycolytic metabolism via the Warburg effect [21,22]. Our results thus demonstrate that autophagy inhibition in BA145 treated PC-3 cells is able to block this Stat-3 activation under hypoxic conditions (Figure 4E).

\section{Autophagy inhibition accentuates the inhibitory effects of BA145 on angiogenesis as well as on tumor cell colony formation}

We used ex vivo and in vitro models to explore the role of BA145 triggered autophagy in the regulation of angiogenesis. First, we found in an aortic ring assay that autophagy inhibitors enhanced the BA145 mediated suppression of microvessel sprouting (Figures 5A and 5C). Secondly, in a capillary tube formation assay, it was observed that BA145 abolished VEGF induced tube formation by HUVEC cultures and co-treatment with autophagy inhibitors intensified this effect (Figures $5 \mathrm{~B}$ and $5 \mathrm{C}$ ). And thirdly, in a wound healing cell assay, it was demonstrated that the effect of BA145 in the inhibition of VEGF induced HUVECs migration was potentiated by autophagy inhibitors (Additional file 1: Figure S7). BA145 treatment also decreased the colony forming ability of PC-3 cells, and the numbers of colonies were significantly decreased during the combinatorial treatment with ammonium chloride, LY294002, or 3-MA (Figure 5D). Importantly, individual treatments with autophagy inhibitors showed no effect on colony formation (Additional file 1: Figure S8A).

\section{Autophagy inhibition promotes the anti-angiogenic effects of BA145 in vivo}

Based on the previously described in vitro experiments, we next wanted to determine whether a similar role exists for autophagy inhibitors in BA145 regulation of angiogenesis in vivo using the Matrigel plug assay. As shown in Figure 6A, Matrigel plugs containing VEGF are dark red in color due to the formation of a functional vasculature. As expected, treatment with BA145 inhibited angiogenesis, as indicated by the faint color of the Matrigel plugs. Chloroquinone (CQ), an antimalarial drug is known to inhibit autophagy by preventing the acidification of lysosomes, which itself impairs the activity of lysosomal proteases and hence the autophagic degradation process [23]. Co-treatment with CQ and BA145 was able to prominently block Matrigel vasculature formation beyond that of BA145 alone (Figure 6A). H\&E staining of the formed vasculature in the Matrigel plugs further confirmed that autophagy inhibition by CQ greatly enhanced the antiangiogenic activity of BA145 (Figures 6B and C).

\section{Autophagy inhibitors potentiate the antitumor effect of BA145}

Given the success of using CQ to augment the antiangiogenic properties of BA145, we next determined whether CQ could similarly augment the therapeutic efficacy of BA145 against aggressive PC-3 M-luc2 xenografts in NOD.SCID mice. It was observed that the mean tumor volume increased in control mice from $69.0 \pm 18.5 \mathrm{~mm}^{3}$ on day 18 to $984.16 \pm 100.62 \mathrm{~mm}^{3}$ on day 46 . This was compared to the 28 day treatment with BA145 that resulted in a tumor volume increase of $60.0 \pm 14.68 \mathrm{~mm}^{3}$ to $710 \pm 77.48 \mathrm{~mm}^{3}$ (28\% inhibition), and the combination treatment of BA145 and CQ that resulted in a tumor volume increase of $64.0 \pm 13.7 \mathrm{~mm}^{3}$ to $410.8 \pm 36 \mathrm{~mm}^{3}$ (58\% inhibiton) (Figures 6D and E). Additionally, the average weight of the excised tumors was $0.85 \pm 0.15 \mathrm{~g}$ in control mice, $0.65 \pm 0.14 \mathrm{~g}$ in BA145 treated mice, and $0.22 \pm 0.1 \mathrm{~g}$ in mice treated with both BA145 and CQ (Figure 6E). Interestingly, it was observed that BA145 and CQ cotreatment did not have any significant effect on the body weight of mice (Additional file 1: Figure S8B). Flutamide, an anti-androgen used in the treatment of prostate cancers, was used as a positive control group during the experiment, while CQ at a dose of $50 \mathrm{mg} / \mathrm{kg}$ was non-toxic to mice (Figure 6D).

\section{Inhibition of autophagy enhances the suppression of pro-angiogenesis factors and associated tumor burden in BA145 treated mice}

To explore the mechanism by which CQ improved the anti-tumor efficacy of BA145, we examined the changes in angiogenic and apoptotic signals in tumor tissues. Hence, tumor tissues were harvested and lysed in order to monitor the expression of angiogenic and apoptotic factors by western blot analysis. As shown in Figure 6F, BA145 inhibited the activation of VEGFR-2/HIF- $1 \alpha$ / HIF-1 $\beta$ in prostate xenografts while the addition of $C Q$ potentiated this effect. Moreover, co-treatment with CQ and BA145 enhanced the cleavage of procaspase- 3 and PARP-1 in tumor tissues. 


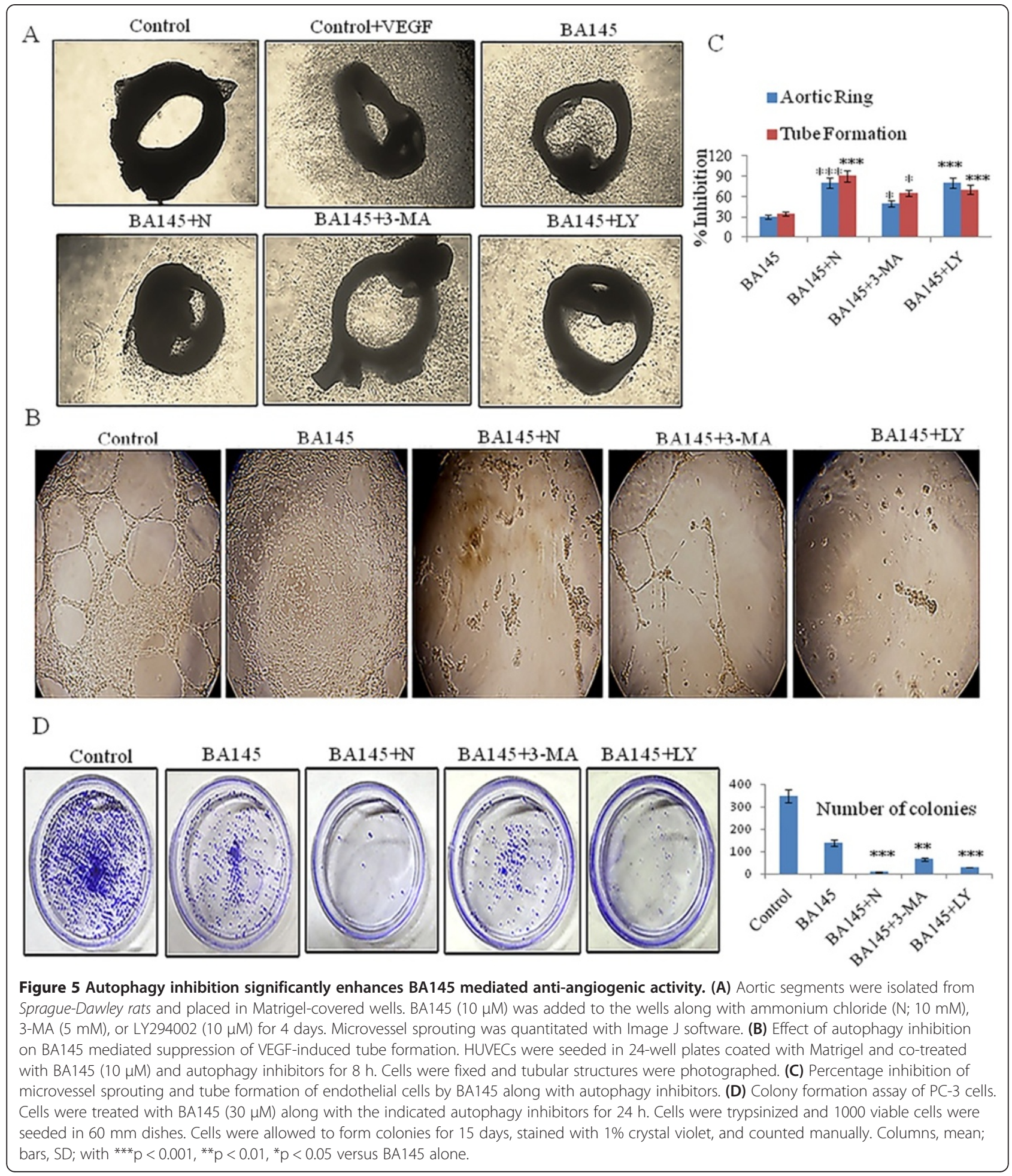

\section{Discussion}

Over the past decade, our understanding of angiogenesis and its role in cancer has increased to a great extent leading to the approval of anti-angiogenic drugs for the treatment of cancer $[1,4]$. However, many tumors develop drug resistance with progression of the disease occurring after just a few months of treatment $[24,25]$. The molecular mechanism of resistance is not well understood as there are many factors which may play role in this process. Several studies have demonstrated that autophagy plays a crucial role in cell survival and resistance to external stress. Regarding tumors, there are several contentious reports 
A
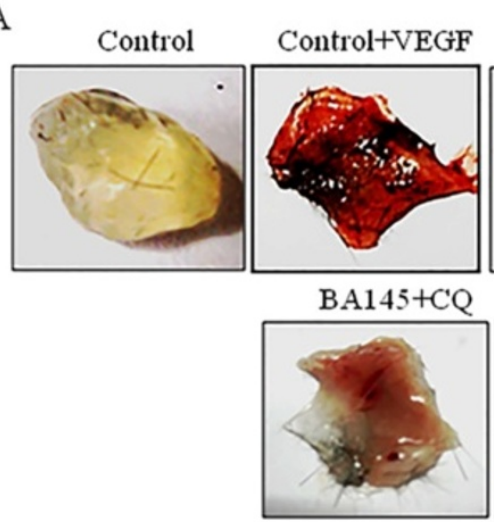

C

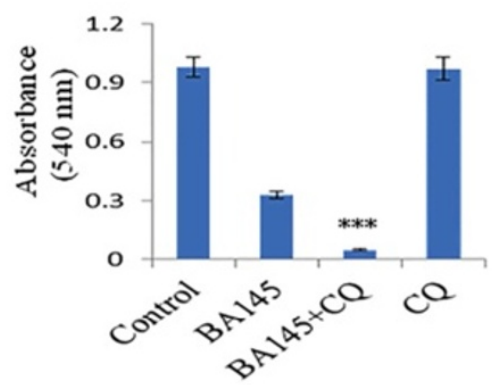

E
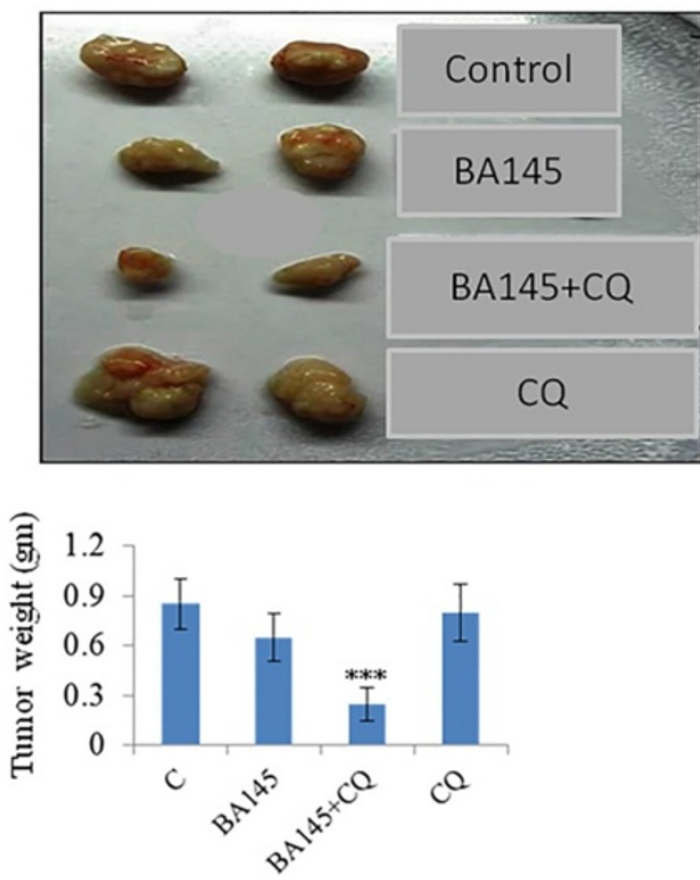

D

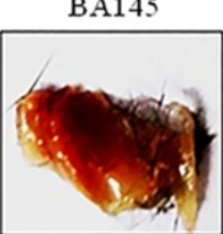

CQ

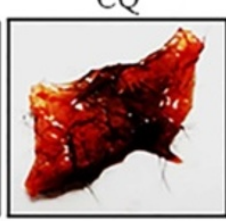

B
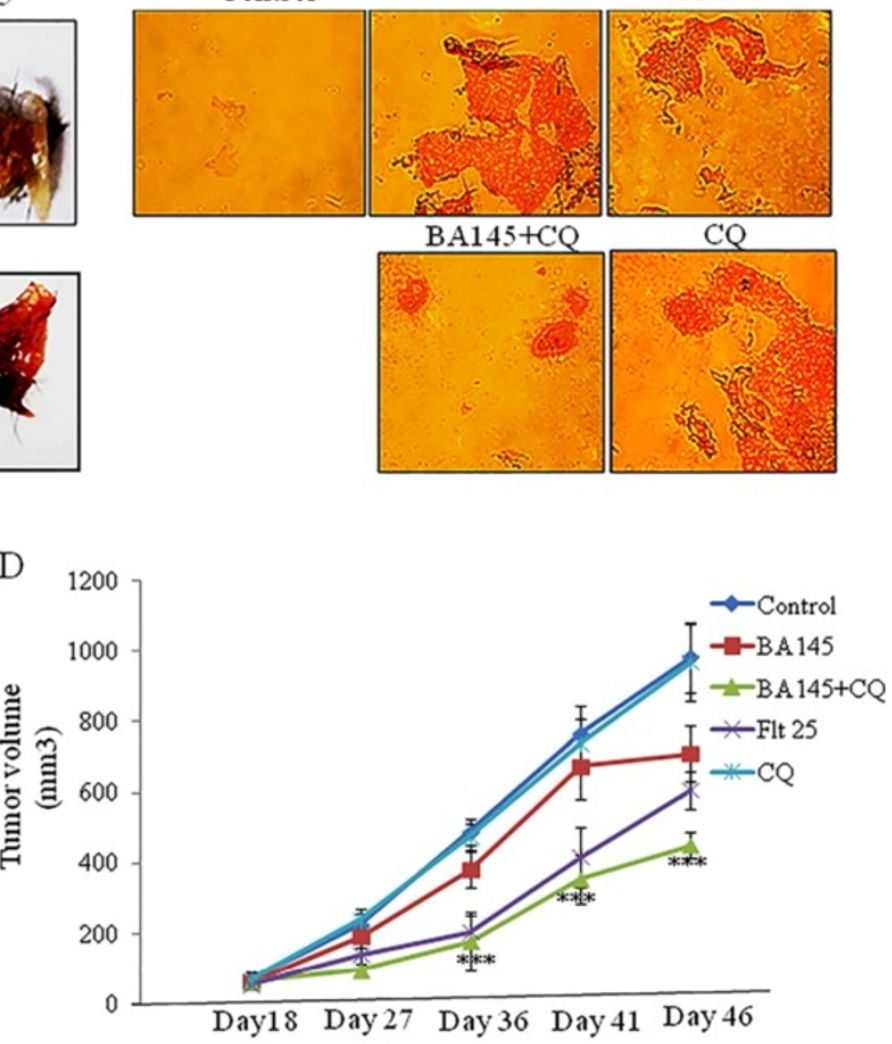

F

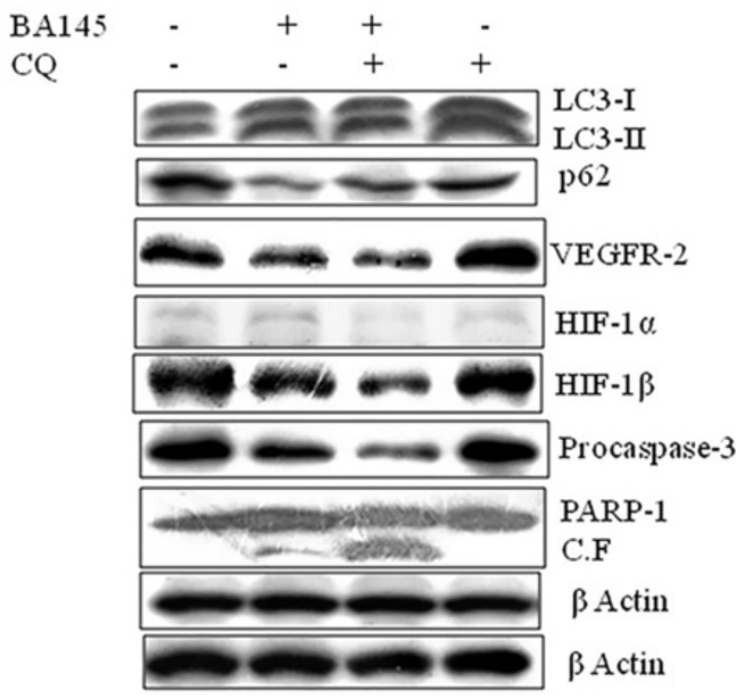

Figure 6 (See legend on next page.) 


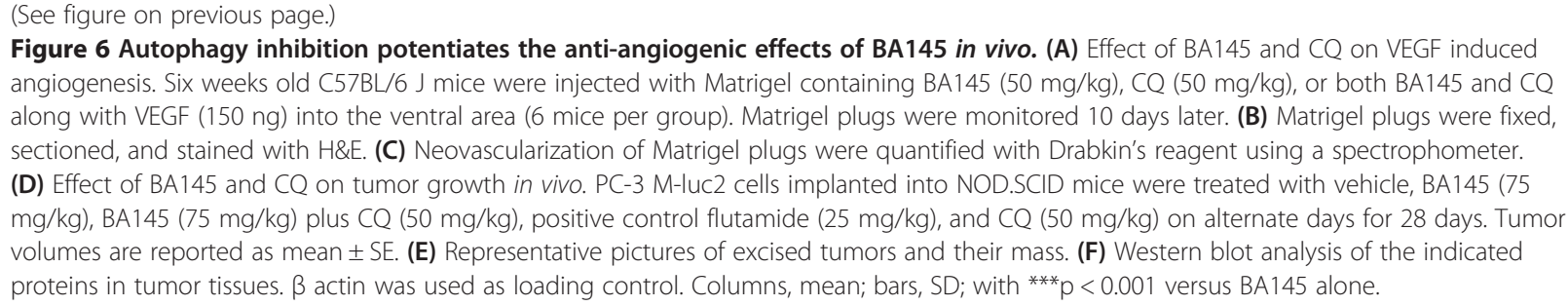

regarding the role of autophagy in angiogenesis and cancer cell death. Although some studies have shown that the autophagy is a different form of cell death [26,27], others have reported that it is a protective mechanism against chemotherapy related toxicity [28,29]. In our studies we used the natural compound derivative BA145, a robust autophagy inducer, to investigate the complex association between autophagy, angiogenesis, and cell fate. We are reporting for the first time that BA145 induced autophagy in cancer cells is cytoprotective in nature, and confers protection against the cytotoxic and antiangiogenic properties of BA145. Using different in vitro, ex vivo and experimental mouse models, we have shown that BA145 triggered autophagy promotes cytoprotection and angiogenesis. We further show that combinatorial treatments involving BA145 and autophagy inhibitors can be exploited for enhanced tumor cytotoxicity.

BA145 triggered the apoptotic cell death of PC-3 cells and HUVECs based on an observed increase in SubG1 cell populations, a loss in MMP, PARP-1 cleavage, and activation of caspases. BA145 also exhibited anti-angiogenic properties by suppressing VEGF signaling both in vitro and in vivo. This included the expression of the pro-angiogenic drivers VEGFR-1 and VEGFR-2 as well as several downstream signaling components like HIF- $1 \alpha$, HIF-1 $\beta$, Src, and FAK. It was further observed that BA145 triggered robust autophagy in PC-3 cells and HUVECs as observed by microscopy, flow cytometry, and the expression of key autophagy proteins. While the role of autophagy in cell death and survival is controversial, our findings conducted in PC-3 cells and HUVECs demonstrated that BA145 induced autophagy is cytoprotective and its inhibition through siRNA or pharmacological inhibitors (e.g. ammonium chloride, 3-MA, or LY294002) augmented the anti-angiogenic and proapoptotic effects of BA145. We further demonstrated that the consequences of BA145 triggered autophagy on cell fate was cell line specific. In the case of HCT116 and COLO205 colon cancer cells, MCF-7 breast cancer cells, and SH-SY5Y neuroblastoma cells, BA145 induced autophagy remained cytoprotective in nature and cytotoxicity was enhanced by autophagy inhibitors. However, in PANC-1 and Mia PaCa-2 cancer cells, autophagy inhibition did not show any significant effect on BA145 mediated cytotoxicity. In MDA-MB-231 breast cancer cells, autophagy inhibition by LY294002 actually decreased BA145 induced cytotoxicity.

Inhibition of autophagy in BA145 treated PC-3 cells enabled significant downregulation of VEGF induced angiogenic signaling compared to BA145 alone. Furthermore, the expression levels of intracellular and extracellular VEGF in PC-3 cells was also diminished. Stat-3 is a point of convergence for many signaling pathways involved in cell proliferation, tumor growth, and angiogenesis [30], and its expression correlates with the expression of VEGF in human cancer cell lines [31]. Activated Stat-3 also mediates the up-regulation of HIF- $1 \alpha$ by increasing its stability and transcriptional activity [31]. Interestingly, it was also observed that under conditions of hypoxia, the expression of HIF-1, Stat-3 and VEGF proteins were significantly reduced by combinatorial treatments of BA145 and autophagic inhibitors as compared to BA145 alone. This indicates that autophagy can promote the expression of these pro-survival and pro-angiogenic proteins. The addition of autophagy inhibitors significantly enhanced the anti-angiogenic effects of BA145 as evidenced by reduced capillary like structures, microvessel sprouting and migration in HUVECs. Autophagy inhibition in PC-3 cells enhanced the inhibitory effect of BA145 on colony formation. In mouse models, autophagy inhibition by CQ cooperated with BA145 to completely block vascular formation. And in highly aggressive prostate cancer xenografts in NOD-SCID mice, treatment with BA145 and CQ suppressed tumor growth by $58 \%$, an over 2 -fold enhancement relative to BA145 treatment alone. Expression analysis of tumor samples for key angiogenic and autophagy factors revealed that autophagy inhibition by CQ significantly potentiated the negative regulation of BA145 on VEGFR-2, HIF- $1 \alpha$, and HIF- $1 \beta$, and increased pro-apototic signals. Similarly, inhibiting autophagy in sunitinib treated PC-3 cells and HUVECs greatly enhanced the antiproliferative activity of sunitinib against cancer cells. Consistent with previous studies, it was found that sunitinib treatment increased VEGFR-2 and HIF- $1 \alpha$ expression in PC-3 cells [32-34]. This enhanced expression of HIF-1 $\alpha$ may be due to the creation of hypoxia, which plays a critical role in the development of angiogenic drug resistance. Our results further demonstrated 
that the inhibition of autophagy with ammonium chloride in sunitinib treated PC-3 cells led to the supression of angiogenesis as evidenced by the significant decrease in VEGFR-2, HIF- $1 \alpha$, and HIF- $1 \beta$ expression.

\section{Conclusion}

Development of cellular resistance against available anticancer or anti-angiogenic agents is a major challenge in the successful treatment of this disease. Understanding the basis of this resistance is critical to the development of novel and effective therapies. During this study, we found that autophagy is one of the mechanisms by which cancer cells protect themselves against cytotoxic or antiangiogenic agents. Our results showed that the autophagy triggered by the anti-cancer agents BA145 or sunitinib was not only initiated as a survival mechanism, but also promoted angiogenesis. Together these findings suggest that it is important to understand the role of autophagy on cell fate in various cancers triggered by potential anticancer agents. A combination of autophagy inhibitors can be useful in enhancing the therapeutic efficacy of these agents and should be further tested in clinical settings.

\section{Methods}

\section{Reagents and Antibodies}

RPMI-1640, MEM, propidium iodide (PI), rhodamine-123 (Rh-123), acridine orange, 3-(4, 5- dimethylthiazole-2-yl)2,5 diphenyltetrazolium bromide (MTT), phenylmethanesulfonyl fluoride (PMSF), 3-methyl adenine (3-MA), chloroquinone (CQ), ammonium chloride, bafilomycin, cobalt chloride, sodium fluoride, kanamycin, streptomycin, fetal bovine serum (FBS), $\beta$-mercaptoethanol, and human VEGF were purchased from Sigma-Aldrich, Missouri, USA. Growth factor reduced Matrigel were from BD Biosciences, New Jersey, USA. Antibodies for casapse-8, caspase-9, caspase-3, PARP-1, and $\beta$-Actin were from Santa Cruz Biotechnology, Texas, USA. All other antibodies and LY294002 were purchased from Cell Signaling Technology, Massachusetts, USA. Electrophoresis reagents, reagents for protein estimation, and protein molecular weight markers were from Bio-Rad Laboratories, California, USA.

\section{Cell Culture and Treatments}

The human prostate cancer cell line PC-3, the colorectal carcinoma cell lines HCT116 and COLO205, the human breast cancer cell lines MCF-7 and MDA-MB-231, the human pancreatic cancer cell lines Panc-1 and Mia PaCa-2, the human neuroblastoma cell line SH-SY5Y and primary human umbilical vein endothelial cells (HUVECs) were purchased from ECACC, England. Cancer cells were grown in RPMI/MEM/McCOY/DMEM growth media containing $10 \%$ FBS, $100 \mathrm{U}$ penicillin G, and $100 \mu \mathrm{g}$ streptomycin per ml. HUVECs were grown in EndoGRO-LS complete media from Millipore. Cells were grown in a $\mathrm{CO}_{2}$ incubator (Thermocon Electron Corporation, Texas, USA) at $37^{\circ} \mathrm{C}$ with 95\% humidity. BA145, bafilomycin, and LY294002 were dissolved in DMSO (final concentration $<0.2 \%$ ); ammonium chloride, CQ, and 3-MA were solubilized in Milli-Q water.

\section{Cell Proliferation Assay}

Cells were seeded in 96 well plates. When at 70-75\% confluency, cells were treated with different concentrations of BA145 for 24 and $48 \mathrm{~h}$. All inhibitors used in the experiment were added $1 \mathrm{~h}$ before the treatment of BA145. Cell proliferation was assessed by using an MTT assay as previously described [35].

\section{Mitochondrial Membrane Potential (MMP) Loss}

Cells were treated with or without inhibitors at different concentrations for $24 \mathrm{~h}$. Mitochondrial membrane potential loss ( $\Psi \mathrm{mt})$ was analyzed by using the fluorescent probe rhodamine 123 as previously described [11].

\section{Wound Healing Migration Assay}

Cells were seeded in 6 well plates. When at $80 \%$ confluency, a micro tip was used to draw a scratch across the center of the culture plate to produce a clean wound area. Cells were incubated with BA145 for 8-10 h, and cell migration was examined under the microscope (Olympus Imaging) by manual counting.

\section{Colony Formation Assay}

Cells were treated with BA145 in the presence or absence of autophagic inhibitors at different concentrations for $24 \mathrm{~h}$. Cells were then trypsinized, viable cells were counted, and 1000 cells were seeded in $60 \mathrm{~mm}$ dishes for 15 days to determine the effect of these compounds on clonogenic survival. The colonies were fixed in $4 \%$ formaldehyde for $15-20 \mathrm{~min}$, stained with $1 \%$ crystal violet, and the colonies counted.

\section{Enzyme-linked Immunosorbent Assay (ELISA) for VEGF}

PC-3 cells were seeded in $60 \mathrm{~mm}$ dishes. When at 90-95\% confluency, cells were treated with BA145 in the presence or absence of autophagic inhibitors and incubated under hypoxic or normoxic conditions for $16 \mathrm{~h}$. Supernatants from the media were collected and the VEGF concentration was determined according to manufacturer guidelines using a VEGF ELISA kit from R\&D Systems (\#DVE00), Minnesota, USA.

\section{Capillary-like Tube Formation Assay}

A tube formation assay was performed by using an in vitro angiogenesis assay kit (Millipore, \#ECM 625) according to manufacturer guidelines. Briefly, the extracellular matrix was diluted with diluents buffer before use at $4^{\circ} \mathrm{C}$, and 
$50 \mu \mathrm{l}$ of this solution was transferred to each well of a precooled 96 well plate. The plate was placed in an incubator at $37^{\circ} \mathrm{C}$ for at least $1 \mathrm{~h}$ to allow the solidification of the matrix solution. HUVECs were trypsinized, and 50008000 cells were seeded in each matrix coated well, followed by overnight incubation at $37^{\circ} \mathrm{C}$. Cells were treated with BA145 and autophagic inhibitors for $10 \mathrm{~h}$. Tube formation was observed under the light microscope at 10X magnification equipped with a digital camera (Olympus Imaging), and were counted manually.

\section{Aortic Ring Assay}

A rat aortic ring assay was performed as previously described [36]. Briefly, Sprague Dawley rats were obtained from the central animal facility of the institute. Rats were sacrificed by cervical dislocation and aortas were isolated, precleaned from periadventitial fat, and cut into rings at 1 to $1.5 \mathrm{~mm}$ in circumference under aseptic conditions. The aortic rings were embedded in Matrigel with or without VEGF $(20 \mathrm{ng} / \mathrm{ml})$, followed by treatment with BA145 $(10 \mu \mathrm{M})$ alone or in combination with LY294002 $(10 \mu \mathrm{M}), 3-\mathrm{MA}(5 \mathrm{mM})$ and ammonium chloride $(10 \mathrm{mM})$ for 4 days. Microvessel sprouts were fixed, photographed using an Olympus IX70 inverted microscope, and counted using Image J software [36].

\section{In Vivo Angiogenesis Assay}

A Matrigel plug assay was performed as previously described [37]. Briefly, $0.5 \mathrm{ml}$ ice cold Matrigel (BD Biosciences) was injected subcutaneously along with VEGF-A (150 ng/mL), BA145 (50 mg/Kg body weight (BW), and/ or CQ (50 mg/kg BW) into C57/BL6J male mice (2025 g, 4-6 weeks old). After 10 days, mice were sacrificed in order to remove the Matrigel plugs and photographs were taken. The neovascularization of the Matrigel plugs was quantified using Drabkin's reagent and the absorbance was measured spectrophotometerically at $540 \mathrm{~nm}$ in order to estimate hemoglobin $(\mathrm{Hb})$ where $\mathrm{Hb}(\mathrm{g} / \mathrm{dl})=$ absorbance of sample/absorbance of standard $\times$ concentration of standard. All mice were obtained from the central animal facility of the institute. Mice were housed and cared under standard conditions and animal studies were performed according to experimental protocols approved by the Institutional Animal Ethics Committee (IAEC).

\section{Tumor Studies}

The antitumor efficacy of BA145 and the autophagic inhibitor CQ were examined against human prostate cancer xenografts in mice. Male NOD.SCID mice (18-23 g) were procured from the animal facility of the institute and were housed in a sterile microenvironment. The number of animals and the protocols used in this study were approved by the IAEC. PC-3 M-luc2 cells $\left(3 \times 10^{6}\right)$ were suspended in PBS, mixed with an equal volume of
Matrigel, and injected subcutaneously into the right flanks of each animal on day 0 . Tumor growth was monitored on every alternate day and animals bearing 50-100 mg tumor mass were selected for the experiment on the staging day (day 18). Mice were randomly distributed into 5 different groups with 6 mice in each group. Group I was administered $0.2 \mathrm{ml}$ normal saline (i.p.), and served as an untreated control. Group II was treated with BA145 (75 mg/kg i.p.) on every alternate day. Group III was administered BA145 (75 mg/kg i.p.) and CQ (50 mg/kg i.p.) on every alternate day. Group IV was administered flutamide ( $25 \mathrm{mg} / \mathrm{kg}$ p.o.), and served as a positive control. Group V was administered with CQ (50 mg/kg i.p.) on every alternate day. Tumors volumes were calculated as described earlier [38]. On day 46, all animals were sacrificed and tumors were excised. Cell lysates were prepared from the harvested tumors using RIPA buffer for western blotting.

\section{Immunofluorescence and Confocal Microscopy}

PC-3 cells were grown on coverslips and treated with BA145 at different concentrations for $24 \mathrm{~h}$. Cells were fixed, stained, and analyzed under the fluorescent microscope as previously described [11].

\section{Preparation of Cell Lysates and Western Blot Analysis}

The preparation of cell lysates and protein specific immunoblotting was performed as previously described [11].

\section{Statistical Analysis}

Data are presented as means of three similar experiments and the error bars represent the standard deviation (SD) between the experiments. Statistical analysis was done using the Bonferroni method and a p value $<0.05$ was considered to be significant $\left.{ }^{* * *} \mathrm{p}<0.001,{ }^{* *} \mathrm{p}<0.01,{ }^{*} \mathrm{p}<0.05\right)$.

\section{Additional file}

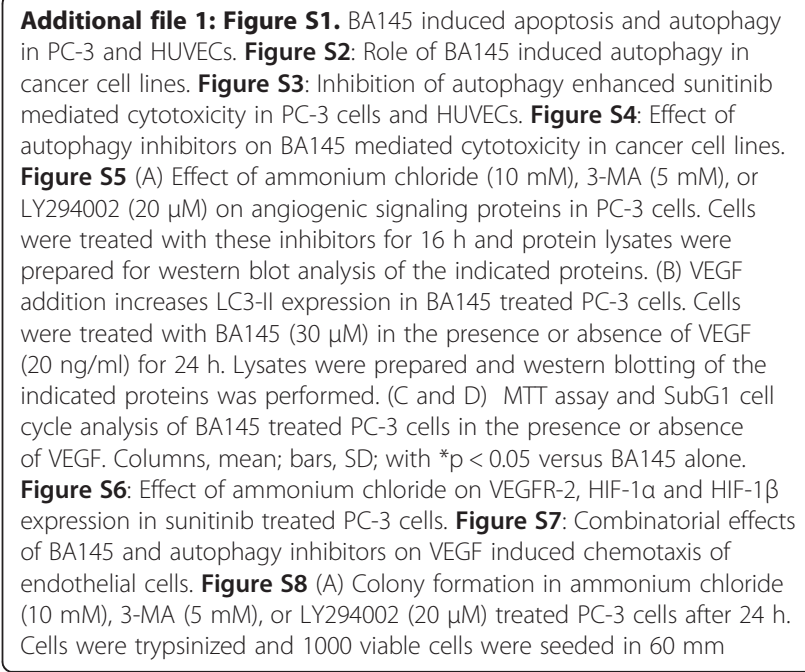


dishes. Cells were allowed to form colonies for 15 days after which colonies were stained with $1 \%$ crystal violet and photographed. (B) Body weight changes in mice treated with BA145, CQ, and/or flutamide (Flt25). There was no significant difference in body weight between the treated groups and the control group in this study.

\section{Abbreviations}

AO: acridine orange; LC3: microtubule-associated protein light chain 3; MTT: 3-(4,5-Dimethylthiazole-2-y)-2,5-diphenyltetrazolium bromide; PI: propidium iodide; Rh-123: Rhodamine-123; $\mathrm{CoCl}_{2}$ : Cobalt chloride; siRNA: small interfering RNA; HUVECs: human umbilical cord vein endothelial cells; VEGFR: vascular endothelial growth factor receptor; CQ: Chloroquinone; BA145: Boswellic acid analogue.

\section{Competing interests}

The authors declare that they have no competing interests.

\section{Authors' contribution}

ASP performed the experiments. FM and ASP planned and designed the experiments. ZAW and DMM performed the mice xenograft model experiments. SKG and SK performed the in vivo Matrigel plug assay. BKC performed the H\&E staining. FM, ASP and HK analyzed and interpreted the data. HK and DS helped in refining the manuscript. All authors read and approved the final manuscript.

\section{Acknowledgements}

We are thankful to the Council of Scientific and Industrial Research (CSIR), India for financial assistance to carry out this research work, including a research fellowship to ASP. We are also grateful to Dr. PR Sharma for his help in microscopy and Mr. Girish Mahajan for his support during the in vivo studies.

\section{Financial Support}

This work was supported by grants (BSC-205 and P81-113) from the Council of Scientific and Industrial Research (CSIR), India.

\section{Author details}

'Department of Cancer Pharmacology, CSIR-Indian Institute of Integrative Medicine, Canal Road, Jammu, Jammu and Kashmir 180001, India. ${ }^{2}$ Academy of Scientific and Innovative Research (AcSIR), New Delhi 110001, India. ${ }^{3}$ Department of Biochemistry and Molecular Biology, Georgia Regents University Cancer Center, 1410 Laney Walker Boulevard CN2136, Augusta, GA 30912, USA. ${ }^{4}$ Department of Inflammation Pharmacology, Indian Institute of Integrative Medicine, Canal Road, Jammu, Jammu and Kashmir 180001, India. ${ }^{5}$ Department of Biology, Appalachian State University, 572 Rivers Street, Boone, NC 28608, USA.

Received: 24 February 2014 Accepted: 16 December 2014 Published: 21 January 2015

\section{References}

1. Carmeliet P. Mechanisms of angiogenesis and arteriogenesis. Nat Med. 2000;6:389-95

2. Chung AS, Ferrara N. Developmental and pathological angiogenesis. Annu Rev. 2011;27:563-84.

3. Berz D, Wanebo H. Targeting the growth factors and angiogenesis pathways: small molecules in solid tumors. J Surg Oncol. 2011;103:574-86.

4. Albini A, Tosetti F, Li WW, Noonan DM, Li WW. Cancer prevention by targeting angiogenesis. Nat Rev Clin Oncol. 2012;9:498-509.

5. Hu YL, Jahangiri A, De Lay M, Aghi MK. Hypoxia-induced tumor cell autophagy mediates resistance to anti-angiogenic therapy. Autophagy. 2012;8:979-81.

6. Nguyen TM, Subramanian IV, Kelekar A, Ramakrishnan S. Kringle 5 of human plasminogen, an angiogenesis inhibitor, induces both autophagy and apoptotic death in endothelial cells. Blood. 2007:109:4793-802.

7. Ramakrishnan S, Nguyen TM, Subramanian IV, Kelekar A. Autophagy and angiogenesis inhibition. Autophagy. 2007:3:512-5.

8. Du J, Teng RJ, Guan T, Eis A, Kaul S, Konduri GG, et al. Role of autophagy in angiogenesis in aortic endothelial cells. Am J Physiol Cell Physiol. 2012;302:383-91.
9. Shen W, Tian C, Chen H, Yang Y, Zhu D, Gao P, et al. Oxidative stress mediates chemerin-induced autophagy in endothelial cells. Free RadicBiol Med. 2013;55:73-82.

10. Kumar A, Shah BA, Singh S, Hamid A, Singh SK, Sethi VK, et al. Acyl derivatives of boswellic acids as inhibitors of NF-KB and STATs. Bioorg Med Chem Lett. 2012;22:431-5.

11. Pathania AS, Joshi A, Kumar S, Guru SK, Bhushan S, Sharma PR, et al. Reversal of boswellic acid analog BA145 induced caspase dependent apoptosis by PI3K inhibitor LY294002 and MEK inhibitor PD98059. Apoptosis. 2013;18:1561-73.

12. Yadav VR, Prasad S, Sung B, Gelovani JG, Guha S, Krishnan S, et al. Boswellic acid inhibits growth and metastasis of human colorectal cancer in orthotropic mouse model by down regulating inflammatory, proliferative, invasive and angiogenic biomarkers. Int J Cancer. 2012;130:2176-84.

13. Pang $X$, Yi Z, Zhang X, Sung B, Qu W, Lian X, et al. Acetyl-11-keto-beta-boswellic acid inhibits prostate tumor growth by suppressing vascular endothelial growth factor receptor 2-mediated angiogenesis. Cancer Res. 2009;69:5893-900.

14. Russo G, Mischi M, Scheepens W, De la Rosette JJ, Wijkstra H. Angiogenesis in prostate cancer: onset, progression and imaging. BJU Int. 2012;1 10:E794-808.

15. Krock BL, Skuli N, Simon MC. Hypoxia-induced angiogenesis: good and evil. Genes Cancer. 2011;2:1117-33.

16. Facciabene A, Peng X, Hagemann IS, Balint K, Barchetti A, Wang LP, et al. Tumor hypoxia promotes tolerance and angiogenesis via CCL28 and T(reg) cells. Nature. 2011;475:226-30.

17. Brader S, Eccles SA. Phosphoinositide 3-kinase signaling pathways in tumor progression, invasion and angiogenesis. Tumori. 2004;90:2-8.

18. Lu Z, Luo RZ, Lu Y, Zhang X, Yu Q, Khare S, et al. The tumor suppressor gene ARHI regulates autophagy and tumor dormancy in human ovarian cancer cells. J Clin Invest. 2008;118:3917-29.

19. Hu YL, DeLay M, Jahangiri A, Molinaro AM, Rose SD, Carbonell WS, et al. Hypoxia-induced autophagy promotes tumor cell survival and adaptation to anti-angiogenic treatment in glioblastoma. Cancer Res. 2012;72:1773-83.

20. Pugh CW, Ratcliffe PJ. Regulation of angiogenesis by hypoxia: role of the HIF system. Nat Med. 2003;9:677-84.

21. Demaria M, Poli V. PKM2, Stat-3 and HIF-1a- The Warburg's vicious circle. JAK- STAT. 2011;1:194-6.

22. Yu H, Kortylewski M, Pardoll D. Crosstalk between cancer and immune cells: role of Stat-3 in the tumor microenvironment. Nat Rev Immunol. 2007;7:41-51.

23. Khraishi MM, Singh $\mathrm{G}$. The role of antimalarials in rheumatoid arthritis - the American experience. Lupus. 1996;5:\$41-4.

24. Bergers $G$, Hanahan D. Modes of resistance to anti-angiogenic therapy. Nat Rev Cancer. 2008;8:592-603.

25. Loges $S, S$ Schmidt T, Carmeliet P. Mechanisms of resistance to anti-angiogenic therapy and development of third-generation anti-angiogenic drug candidates. Genes Cancer. 2010;1:12-25.

26. Maiuri MC, Zalckvar E, Kimchi A, Kroemer G. Self-eating and self killing: crosstalk between autophagy and apoptosis. Nat Rev Mol Cell Biol. 2007;8:741-52.

27. Hippert MM, O'Toole PS, Thorburn A. Autophagy in cancer: good, bad, or both? Cancer Res. 2006;66:9349-51.

28. Mancias JD, Kimmelman AC. Targeting autophagy addiction in cancer. Oncotarget. 2011;2:1302-6.

29. Buchser WJ, Laskow TC, Pavlik PJ, Lin HM, Lotze MT. Cell-mediated autophagy promotes cancer cell survival. Cancer Res. 2012;72:2970-9.

30. Abdulghani J, Gu L, Dagvadorj A, Lutz J, Leiby B, Bonuccelli G, et al. Stat-3 promotes metastatic progression of prostate cancer. Am J Pathol. 2008;172:1717-28.

31. Niu G, Wright KL, Huang M, Song L, Haura E, Turkson J, et al. Constitutive Stat-3 activity up-regulates VEGF expression and tumor angiogenesis. Oncogene. 2002;21:2000-8.

32. Kumar R, Crouthamel MC, Rominger DH, Gontarek RR, Tummino PJ, Levin RA, et al. Myelosuppression and kinase selectivity of multikinase angiogenesis inhibitors. Br J Cancer. 2009;101:1717-23.

33. Kodera Y, Katanasaka Y, Kitamura Y, Tsuda H, Nishio K, Tamura T, et al. Sunitinib inhibits lymphatic endothelial cell functions and lymph node metastasis in a breast cancer model through inhibition of vascular endothelial growth factor receptor 3. Breast Cancer Res. 2011;13:R66.

34. Conley SJ, Gheordunescu E, Kakarala P, Newman B, Korkaya H, Heath AN, et al. Anti-angiogenic agents increase breast cancer stem cells via the generation of tumor hypoxia. ProcNatlAcadSci U S A. 2012;109:2784-9.

35. Kumar S, Kumar A, Pathania AS, Guru SK, Jada S, Sharma PR, et al. Tiron and trolox potentiate the autophagic cell death induced by magnolol analog Ery5 by activation of Bax in HL-60 cells. Apoptosis. 2013;18:605-17. 
36. Nicosia RF, Ottinetti A. Modulation of microvascular growth and morphogenesis by reconstituted basement membrane gel in three-dimensional cultures of rat aorta: a comparative study of angiogenesis in Matrigel, collagen, fibrin, and plasma clot. InVitro Cell Dev Biol. 1990;26:119-28.

37. Min JK, Cho YL, Choi JH, Kim Y, Kim JH, Yu YS, et al. Receptor activator of nuclear factor (NF)-kB ligand (RANKL) increases vascular permeability: impaired permeability and angiogenesis in eNOS-deficient mice. Blood. 2007;15:1495-502

38. Malik F, Kumar A, Bhushan S, Mondhe DM, Pal HC, Sharma R, et al. Immune modulation and apoptosis induction: Two sides of antitumoral activity of a standardised herbal formulation of Withania somnifera. Eur J Cancer. 2009:45:1494-509.

doi:10.1186/1476-4598-14-6

Cite this article as: Pathania et al:: The anti-angiogenic and cytotoxic effects of the boswellic acid analog BA145 are potentiated by autophagy inhibitors. Molecular Cancer 2015 14:6.

\section{Submit your next manuscript to BioMed Central and take full advantage of:}

- Convenient online submission

- Thorough peer review

- No space constraints or color figure charges

- Immediate publication on acceptance

- Inclusion in PubMed, CAS, Scopus and Google Scholar

- Research which is freely available for redistribution 